\title{
Nutritional and metabolic modulation in chronic obstructive pulmonary disease management
}

\author{
A.M.W.J. Schols
}

\begin{abstract}
Nutritional and metabolic modulation in chronic obstructive pulmonary disease management. A.M.W.J. Schols. (C) ERS Journals Ltd 2003.

ABSTRACT: In this paper the perspective for nutritional modulation of systemic impairment in patients with chronic obstructive pulmonary disease (COPD) is discussed. Progressive weight loss is characterised by disease-specific elevated energy requirements unbalanced by dietary intake. Weight gain per se can be achieved by caloric supplementation while future studies may prove efficacy of amino acid modulation to stimulate protein synthesis and enhance muscle anabolism.

Disproportionate muscle wasting resembles the cachexia syndrome as described in other chronic wasting diseases (cancer, chronic heart failure, acquired immunodeficiency syndrome (AIDS)). There is yet no adequate nutritional strategy available to treat cachexia in COPD. Muscle substrate metabolism has hardly been investigated, but the few data available point towards a decreased fat oxidative capacity that may show similarities with the "metabolic syndrome" as described in type II diabetes and obesity and could theoretically benefit from polyunsaturated fatty acid modulation.

To adequately target the different therapeutic options, clearly more clinical (intervention) studies are needed in chronic obstructive pulmonary disease patients that are adequately characterised by local and systemic impairment and in which molecular and metabolic markers are linked to functional outcome.

Eur Respir J 2003; 22: Suppl. 46, 81s-86s.
\end{abstract}

Correspondence: A.M.W.J. Schols

Department of Respiratory Medicine University Hospital Maastricht

P.O. Box 5800

6202 AZ Maastricht

Fax: 31433875051

E-mail: a.schols@pul.unimaas.nl

Keywords: Body weight

chronic obstructive pulmonary disease metabolism

muscle

nutrition

Received and accepted June 302003
Nutritional screening and therapy is nowadays considered as an essential component of integrated chronic obstructive pulmonary disease (COPD) management. In particular systemic manifestations of COPD are potential targets for intervention. The present paper aims to present current insight into the efficacy of dietary supplementation to reverse weight loss and muscle wasting in COPD as well as to discuss the perspective for nutritional modulation of altered muscle metabolism. In addition the question will be addressed to what extent these systemic manifestations in COPD should be regarded as disease specific, or represent generalised phenomena of chronic disease.

\section{Modulation of energy balance}

\section{Loss of body weight and fat mass}

The association between underweight and increased mortality risk has been well established in numerous retrospective studies ranging from selected COPD patients to populationbased samples [1-3]. Two prospective studies even showed in COPD patients with a body mass index below $25 \mathrm{~kg} \cdot \mathrm{m}^{-2}$ that weight gain was associated with decreased mortality risk [2, 4]. It is not fully understood why COPD patients become underweight but weight loss and specifically loss of fat mass, is generally the result of a negative energy balance and appears to be more prevalent in patients with emphysema [5]. In contrast to an adaptive decreased energy metabolism during (semi) starvation, increased resting energy requirements have been observed in some of the COPD patients, linked to low-grade systemic inflammation [6, 7]. Studies in other chronic wasting diseases characterised by hypermetabolism and systemic inflammation (e.g. cancer, chronic heart failure, acquired immunodeficiency disease syndrome (AIDS)) have shown an adaptive decrease in activity-induced energy expenditure so that daily energy expenditure is normal. In contrast, elevated activity induced and daily energy expenditure has been measured in free-living ambulatory COPD patients [8]. The cause of this disease-specific increase in energy metabolism is not yet clear. A decreased mechanical efficiency of leg exercise has been described that could result from a decreased efficiency of skeletal muscle energy metabolism. Furthermore some studies reported an increased oxygen cost of respiratory muscle activity due to lung hyperinflation. An obvious choice to improve energy balance might thus be to decrease energy expenditure. However, according to the recent Global Initiative for Obstructive Lung Disease (GOLD) guidelines, pulmonary rehabilitation is evidence based and exercise training a key intervention to improve limited functional abilities and maintain an active lifestyle [9]. Since COPD patients may have an elevated energy metabolism and should at the same time be advised to increase exercise, restricting energy output will be hard to realise and may not be desirable. This implies that COPD patients who suffer from weight loss, and even some weight stable patients, should be encouraged to increase their apparently normal energy intake. This could avoid weight loss, specific loss of muscle mass, and a related decrease in functional ability, or could help them regain weight. Besides optimising the treatment of patients who are already underweight, it is therefore important to detect and reverse 
involuntary weight loss in order to avoid functional decline. This may be achieved by increasing dietary intake per se or by altering dietary habits to include different (energy-dense) foods and optimum timing of meals/snacks in relation to symptoms and activity patterns.

Substrate oxidation and ventilation are intrinsically related and theoretically meal-related dyspnoea and impaired ventilatory reserves might restrict the caloric amount and specifically the carbohydrate content of nutritional support in respiratory disease. Earlier studies indeed showed adverse effects of a carbohydrate-rich energy overload on carbon dioxide production and exercise capacity [10], but these results were not confirmed when using a normal energy load [11]. In fact even positive effects of a carbohydrate-rich supplement relative to a fat-rich supplement on lung function and dyspnoea sensation were reported [12].

\section{Caloric supplementation versus dietary change}

Nutritional interventions for COPD patients have focussed mainly on therapeutic caloric support, but few well-controlled studies (i.e. randomised controlled trials (RCTs)) have so far been conducted. FERREIRA et al. [13] have recently reviewed the available studies on therapeutic dietary supplementation in a meta-analysis. They managed to select only six RCTs that were considered to be of sufficient quality, of which two were double-blinded. The pooled effects, based on the analysis of a total of 277 subjects, as well as the results of the individual studies, showed that the effect of nutritional support on anthropometrics was minor at best and generally did not achieve clinical importance or statistical significance. Five of these studies used oral supplementation and four were conducted among outpatients. These results contradict to some extent the results reported by BALDWIN et al. [14], who reviewed the literature on dietary advice and supplementation interventions for patients with disease-related malnutrition in general (including COPD). Their conclusion was that dietary supplementation resulted in better effects on body weight than dietary advice. The review by FERREIRA et al. [13] made no distinction between what may be called "failure to intervene" on the one hand and "failure of the intervention" on the other. In some of the papers on which the metaanalysis was based, patients took the prescribed dietary supplements to replace regular meals instead of as additional calorie input. In such cases the intervention did not succeed in a relevant increase in energy intake and therefore no weight gain could be expected. In the studies that did accomplish to increase energy intake, functional improvements were also observed. Further, studies investigating the effect of dietary supplementation were often conducted among severe COPD cases, in whom besides a negative energy balance, also a specific negative protein balance is often observed (as discussed below). Nevertheless, the meta-analysis and related studies do show that increasing energy intake among severe COPD cases is difficult to accomplish, and if energy intake is not increased, weight and functionality will certainly not improve. Interventions should also be extended to prevention and early treatment of weight loss, that is, before patients are extremely wasted. This means expanding the target group to include COPD outpatients and primary care patients before they have become underweight, and putting more emphasis on dietary change than on medically prescribed supplementation. Few studies have been published on the possibilities and effects of voluntary dietary change among outpatients. Diet is often part of the focus in self-help or self-management programmes for COPD patients and some of these programmes have been evaluated. However there have not yet been any well-controlled studies of the prevention of weight loss in COPD.

\section{Modulation of substrate metabolism}

\section{Muscle wasting}

Body compositional studies have shown that weight loss is accompanied by significant loss of fat-free mass and that it is specifically the loss of fat-free mass or other measures of muscle mass that are related to impaired skeletal muscle strength and exercise capacity $[15,16]$. These studies have furthermore shown that muscle wasting may also occur in normal weight stable subjects. A recent study even suggested that muscle mass is a better predictor of survival than body weight [17]. Wasting of muscle mass is due to an impaired balance between protein synthesis (anabolism) and protein breakdown (catabolism). Besides nutritional abnormalities and physical inactivity, altered neuro-endocrine response and presence of a systemic inflammatory response may contribute to a negative protein balance in chronic diseases. From a therapeutic perspective it is important to know the relative contribution of these factors to altered protein synthesis and protein breakdown respectively. While increasing dietary intake can compensate elevated energy requirements and vice versa, uncontrolled protein breakdown cannot be overcome by only increasing protein synthesis and vice versa.

\section{Protein metabolism}

Several studies have investigated in COPD and other chronic wasting disorders the effects of pharmacological anabolic stimuli to promote protein synthesis including anabolic steroids, growth hormone and insulin-like growth factor. Discussion of these studies is beyond the scope of this paper. However the fact that most studies in COPD were able to document a modest but significant gain in muscle mass after intervention [18, 19], illustrates that in some of the patients, stimulation of protein synthesis is an effective therapeutic strategy. No studies have yet specifically investigated the ability to induce or enhance muscle weight gain by nutritional modulation of protein synthesis or protein breakdown rates. Optimising protein intake and essential amino acid intake may stimulate protein synthesis per se, but also enhance efficacy of anabolic drugs [20] as well as physiological stimuli such as resistance exercise [21]. Protein requirements in COPD patients and many other chronic diseases are not well established. In normal weight COPD patients, whole body protein synthesis and breakdown rates were elevated compared to a well-matched healthy control group [22]. A potential explanation for this elevated protein turnover is thought to be enhanced acute phase protein synthesis, associated with low-grade inflammation. This is balanced by increased amino acid release from the skeletal muscle compartment (ultimately) resulting in net muscle protein breakdown. Indirect support for this hypothesis is given by two studies that demonstrated a specific association between muscle wasting and markers of systemic inflammation in COPD [23, 7] as well as by another study linking hypermetabolism, increased levels of acute phase proteins and decreased plasma amino acid status [24]. However these studies were merely descriptive and limited by a crosssectional study design. Investigating whole body as well as acute phase protein turnover simultaneously [25] may provide more insight into the proposed link between protein metabolism and systemic inflammation in COPD. Skeletal 
muscle protein turnover has yet been investigated in only one study. Muscle protein synthesis rate was decreased in a group of underweight clinically stable patients with emphysema while protein breakdown rate was normal [26]. This observation fits with the observed positive effects of anabolic pharmacological intervention as well as resistance training on muscle mass during rehabilitation. More studies are needed however to test if these results can be extrapolated to patients with disproportionate muscle wasting.

\section{Amino acids}

Amino acids are the building blocks of protein and several studies have to date reported an abnormal plasma amino acid pattern in COPD. Of interest are the consistently reduced plasma levels of branched chain amino acids (BCAAs) in underweight COPD patients and in those with low muscle mass [27, 28]. There are some indications that low plasma BCAAs in COPD patients are due to specific alterations in leucine metabolism possibly mediated by altered insulin regulation and increased leucine oxidation in skeletal muscle to a noncarbohydrate energy substrate [28]. Leucine is an interesting nutritional substrate since it not only serves as precursor, but also activates signalling pathways that enhance activity and synthesis of proteins involved in messenger ribonucleic acid (RNA) translocation to upregulate protein synthesis in skeletal muscle [29].

In addition to fostering a general higher rate of postprandial protein synthesis, increased availability of amino acids also enhances the stimulation of protein synthesis that occurs in response to exercise [21]. The magnitude of stimulation however depends on the timing of amino acids administration relative to the period of exercise [30]. BCAAs are also important precursors for glutamate (GLU), which is one of the most important non-essential amino acids in muscle. BCAA derived from net protein breakdown and by uptake into the muscle pool, undergo transamination to yield branched-chain keto acid and GLU. Intracellular GLU is involved in numerous metabolic processes including substrate phosphorylation and replenishment of tricarboxylic acid (TCA) intermediates to preserve high-energy phosphates at rest and during exercise. Moreover intracellular GLU is known as an important precursor for antioxidant glutathione (GSH) and glutamine synthesis in muscle [31]. Recently, a consistently reduced muscle GLU status of severe COPD patients was reported [31, 24], that further decreased during a submaximal exercise bout [32]. While muscle redox potential (glutathione disulphide/GSH) increases after endurance exercise training in healthy subjects, patients with COPD showed a reduced ability to adapt in this way as reflected by a lower capacity to synthesise GSH [33]. These observations provide perspective for amino acid supplementation to modulate exercise-induced protein synthesis as well as exercise-induced oxidative stress.

\section{n-3 polyunsaturated fatty acids}

Despite anabolic nutritional and/or pharmacological stimulation, (muscle) weight gain is limited in part of the COPD patients. Like in other chronic inflammatory disorders, poor therapeutic response was related to presence of systemic inflammation [34]. Disproportionate muscle wasting linked to systemic inflammation and unresponsive to nutritional supplementation is commonly referred to as the cachexia syndrome as recently discussed [35]. Current insight into the molecular mechanisms of cachexia indicates a complex interaction between inflammatory mediators, oxidative stress and growth factors, not only involved in an imbalance between muscle protein synthesis and breakdown, but also in processes that govern the maintenance of skeletal muscle and muscle plasticity such as skeletal muscle fibre degeneration, apoptosis and regeneration [35]. These experimental studies may provide in the near future novel pharmacological perspective by specifically targeting crucial mediators of the intracellular signalling pathways involved. But to be able to identify applicability of the proposed mechanisms for COPD (subgroups), a challenge for future human research will be to identify and reliably assess critically regulatory molecules of these processes in muscle biopsies or other tissue to be monitored in clinical comparative and intervention studies.

The fatty acid composition of inflammatory and immune cells is sensitive to change according to the fatty acid composition of the diet. The n-3 polyunsaturated fatty acids (PUFA) eicopentanaenoic acid (EPA) and docosahexaenoic acid are found in high proportions in oily fish and fish oils. The n-3 PUFA are structurally and functionally distinct from the n-6 PUFA. Typically human inflammatory cells contain high proportions of the n-6 PUFA, arachidonic acid and low proportions of n-3 PUFA. The significance of this difference is that arachidonic acid is the precursor of 2-series prostaglandines and 4-series leukotrienes, which are highly-active mediators of inflammation. Feeding fish oil results in partial replacement of arachidonic acid in inflammatory cell membranes by EPA. This change leads to decreased production of arachidonic acid-derived mediators. This response alone is a potentially beneficial anti-inflammatory effect of PUFA. Supplementation of the diet of healthy volunteers with fish oil-derived n-3 PUFA resulted in decreased monocyte and neutrophil chemotaxis and decreased production of proinflammatory cytokines [36]. Clinical studies have reported that fish oil supplementation has beneficial effects on the systemic inflammatory response and disease activity in conditions such as rheumatoid arthritis and inflammatory bowel disease [36]. In patients with cancer cachexia encouraging effects of PUFA supplementation were shown in terms of a decreased systemic inflammatory response and body weight gain [37]. The latter may be related to other effects of $n-3$ PUFA which occur downstream of altered eicosanoid production or might be independent of this activity. Nuclear factor kappa $\mathrm{B}(\mathrm{NF}-\kappa \mathrm{B})$ is a critical mediator of the intracellular signalling events triggered by tumour necrosis factor (TNF)- $\alpha$ and other inflammatory cytokines including skeletal muscle specific gene expression [35]. Recent studies have shown that n-3 PUFA can down-regulate the activity of NF$\kappa B$. The interaction of $n-3$ PUFA and cytokine biology is however complex. In healthy volunteers the sensitivity of a person to the suppressive effects of n-3 PUFA on TNF- $\alpha$ production is linked to the inherent level of production of the cytokines by cells from the person before supplementation and genetic variation encoded by, or associated with the TNF- $\alpha$ -308 and lymphotoxin a +252 single nucleotide polymorphisms [38]. Some studies suggest that TNF- $\alpha$ levels are particularly increased in COPD patients with weight loss and/or muscle wasting [23]. Therapeutic effects of n-3 PUFA in COPD have yet to be determined. In this context it may be relevant to note that TNF- $\alpha-308$ polymorphism has been associated with the presence of COPD [39] and even specifically with the extent of emphysematous changes in these patients [40].

\section{Muscle morphology and metabolism}

Independent of muscle wasting, intrinsic abnormalities in peripheral skeletal muscle morphology and metabolism have 
been described in COPD patients, pointing towards a decreased oxidative capacity. These abnormalities include muscle fibre type shifts from the oxidative type I fibres towards the glycolytic type IIx fibres [41], accompanied by a decrease in oxidative enzymes involved in carbohydrate and fatty acid oxidation [42]. As reviewed elsewhere striking similarities have been observed in these abnormalities between patients with COPD and chronic heart failure [43]. Detailed information of substrate metabolism on whole-body and skeletal muscle level in these diseases is lacking. Nevertheless, the metabolic adaptations have clinical consequence as illustrated e.g. by a decreased mechanical efficiency [44] and enhanced lactic acid production during exercise [45] relative to healthy control subjects. In addition nuclear magnetic resonance studies using single limb exercise models showed a rapid decline and impaired recovery of phosphocreatine stores [46]. Three studies indicated that the decreased oxidative capacity may be more pronounced in patients with emphysema, possibly related to altered oxygen availability [41, 47, 48].

Positive effects of pulmonary rehabilitation, in particular of endurance exercise training, illustrate that decreased muscle oxidative capacity in COPD is at least partly reversible [46], although again detailed information on the effect of endurance training on substrate metabolism in COPD is lacking. While overall effects of endurance type exercise are positive, the available studies also clearly show that it is difficult to enhance this response by modulating exercise type and intensity only [49, 50]. It is therefore tempting to explore the potential of nutritional modulation on muscle substrate metabolism to enhance improvement of exercise capacity in COPD.

\section{Muscle substrate metabolism}

The muscle fibre type shift from type I to type IIx together with the enhanced lactic acid production during exercise points towards a decreased oxidative capacity for specifically fatty acids. This suggestion is consistent with the finding that 3-hydroxyacyl-coenzyme A dehydrogenase (HADH) (an enzyme involved in the $\beta$-oxidation of fatty acids) was shown to be decreased in COPD [42], whereas cytochrome $\mathrm{C}$ oxidase (an enzyme of the respiratory chain) as well as phosphofructokinase (a glycolytic enzyme) was found to be increased in some studies [51, 52]. Disturbances in fat oxidative capacity have also been found in other diseases such as obesity and type 2 diabetes mellitus. These disturbances can be located at the levels of cellular fatty acid uptake, mitochondrial fatty acid uptake and/or fatty acid oxidation. The uptake of fatty acids from the blood into the muscle cell is facilitated by the fatty acid transporters fatty acid translocase (FAT)/CD36 and fatty acid binding protein (FAPBpm) [53]. Impaired expression of fatty acid transporters have indeed been suggested to be involved in the decreased fat oxidative capacity observed in type 2 diabetes mellitus, but data in COPD is lacking [54]. However, it could explain the beneficial effects of endurance training in COPD, as exercise training is able to increase the protein content of FAT/CD36 [55]. Once taken up into the muscle cell, fatty acids need to be taken up into the mitochondria before they can undergo $\beta$-oxidation. Mitochondrial fatty acid uptake is accomplished by carnitine-palmitoyl-transferase-1, the activity of which is under the control of malonyl coenzyme A (malonyl-CoA), the latter being formed out of acetyl-CoA by the enzyme acetyl-CoA carboxylase-2 (ACC2) [56]. It is generally assumed that the mitochondrial uptake of fatty acids is a rate-limiting step in fatty acid oxidation. Endurance training is known to increase fat oxidative capacity and recent data show that ACC2 might be a key factor involved, as endurance training rapidly down-regulates ACC2, allowing increased fat oxidation [57]. Once taken up into the mitochondria, fatty acids can undergo $\beta$-oxidation. The keyenzyme in the $\beta$-oxidation of fatty acids is $\mathrm{HADH}$, which is decreased in skeletal muscle of COPD [42]. The acetyl-CoA formed from the degradation of fatty acids, subsequently enters the TCA cycle, in which the rate-limiting step is the enzyme citrate synthase, which was also shown to be lower in COPD [42]. Future studies are clearly needed to further explore the presence and mechanisms of decreased fat oxidative capacity in COPD. Moreover, these studies may be a further trigger to explore the potential of nutritional modulation on muscle substrate metabolism to enhance improvement of exercise capacity.

\section{Polyunsaturated fatty acids}

Polyunsaturated fatty acids, particularly those of the (n-3) family and to a lesser extent of the (n-6) family, have been shown to specifically alter expression of genes involved in substrate metabolism. They may upregulate the expression of genes encoding proteins involved in fatty acid oxidation while simultaneously down-regulate genes encoding proteins of lipid synthesis [58]. Therefore polyunsaturated fatty acids can be of potential interest in improving oxidative capacity in chronic obstructive pulmonary disease. Polyunsaturated fatty acids govern oxidative gene expression by activation of the transcription factor peroxisome proliferator activated receptor $\alpha$ [59]. This is also the basis for the use of peroxisome proliferator activated receptor agonists in overcoming disturbances in substrate metabolism in insulin resistant disorders (i.e. the metabolic syndrome). The decreased fat oxidative capacity in chronic obstructive pulmonary disease can also be explained by the shift in muscle fibre type. In this context, it is very interesting to note that it was very recently shown that overexpression of the peroxisome proliferator activated receptor gamma-coactivator-1 in mice resulted in a complete shift in muscle fibre type from IIx to I [60]. Moreover, endurance training was shown to increase peroxisome proliferator activated receptor gamma-coactivator-1 expression [61]. It is therefore tempting to speculate that peroxisome proliferator activated receptor gamma-coactivator-1 expression might be altered in chronic obstructive pulmonary disease, although no data is yet available.

\section{References}

1. Wilson DO, Rogers RM, Wright EC, Anthonisen NR. Body weight in chronic obstructive pulmonary disease. The National Institutes of Health Intermittent Positive-Pressure Breathing Trial. Am Rev Respir Dis 1989; 139: 1435-1438.

2. Schols AM, Slangen J, Volovics L, Wouters EF. Weight loss is a reversible factor in the prognosis of chronic obstructive pulmonary disease. Am J Respir Crit Care Med 1998; 157: 1791-1797.

3. Landbo C, Prescott E, Lange P, Vestbo J, Almdal TP. Prognostic value of nutritional status in chronic obstructive pulmonary disease. Am J Respir Crit Care Med 1999; 160: $1856-1861$.

4. Prescott E, Almdal T, Mikkelsen KL, Tofteng CL, Vestbo J, Lange P. Prognostic value of weight change in chronic obstructive pulmonary disease: results from the Copenhagen City Heart Study. Eur Respir J 2002; 20: 539-544.

5. Engelen MP, Schols AM, Lamers RJ, Wouters EF. Different patterns of chronic tissue wasting among patients with 
chronic obstructive pulmonary disease. Clin Nutr 1999; 18: 275-280.

6. Nguyen LT, Bedu M, Caillaud D, et al. Increased resting energy expenditure is related to plasma TNF-alpha concentration in stable COPD patients. Clin Nutr 1999; 18: 269-274.

7. Schols AM, Buurman WA, Staal van den Brekel AJ, Dentener MA, Wouters EF. Evidence for a relation between metabolic derangements and increased levels of inflammatory mediators in a subgroup of patients with chronic obstructive pulmonary disease. Thorax 1996; 51: 819-824.

8. Baarends EM, Schols AM, Pannemans DL, Westerterp KR, Wouters EF. Total free living energy expenditure in patients with severe chronic obstructive pulmonary disease. $\mathrm{Am}$ J Respir Crit Care Med 1997; 155: 549-554.

9. Pauwels RA, Buist AS, Calverley PM, Jenkins CR, Hurd SS. Global strategy for the diagnosis, management, and prevention of chronic obstructive pulmonary disease. NHLBI/ WHO Global Initiative for Chronic Obstructive Lung Disease (GOLD) Workshop summary. Am J Respir Crit Care Med 2001; 163: 1256-1276.

10. Ferreira I, Brooks D, Lacasse Y, Goldstein R. Nutritional intervention in COPD: a systematic overview. Chest 2001; 119: 353-363.

11. Akrabawi SS, Mobarhan S, Stoltz RR, Ferguson PW. Gastric emptying, pulmonary function, gas exchange, and respiratory quotient after feeding a moderate versus high fat enteral formula meal in chronic obstructive pulmonary disease patients. Nutrition 1996; 12: 260-265.

12. Vermeeren MA, Wouters EF, Nelissen LH, van Lier A, Hofman Z, Schols AM. Acute effects of different nutritional supplements on symptoms and functional capacity in patients with chronic obstructive pulmonary disease. $\mathrm{Am}$ J Clin Nutr 2001; 73: 295-301.

13. Ferreira IM, Brooks D, Lacasse Y, Goldstein RS. Nutritional support for individuals with COPD: a meta-analysis. Chest 2000; 117: 672-678.

14. Baldwin C, Parsons T, Logan S. Dietary advice for illnessrelated malnutrition in adults. Cochrane Database Syst Rev: 2001: CD002008.

15. Bernard S, LeBlanc P, Whittom F, et al. Am J Respir Crit Care Med 1998; 158: 629-634.

16. Baarends EM, Schols AM, Mostert R, Wouters EF. Peak exercise response in relation to tissue depletion in patients with chronic obstructive pulmonary disease. Eur Respir $J$ 1997; 10: 2807-2813.

17. Marquis K, Debigare R, Lacasse Y, et al. Midthigh muscle cross-sectional area is a better predictor of mortality than body mass index in patients with chronic obstructive pulmonary disease. Am J Respir Crit Care Med 2002; 166: 809-813.

18. Burdet L, de Muralt B, Schutz Y, Pichard C, Fitting JW. Administration of growth hormone to underweight patients with chronic obstructive pulmonary disease. A prospective, randomized, controlled study. Am J Respir Crit Care Med 1997; 156: 1800-1806.

19. Schols AM, Soeters PB, Mostert R, Pluymers RJ, Wouters EF. Physiologic effects of nutritional support and anabolic steroids in patients with chronic obstructive pulmonary disease. A placebo-controlled randomized trial. Am J Respir Crit Care Med 1995; 152: 1268-1274.

20. Basaria S, Wahlstrom JT, Dobs AS. Clinical review 138: Anabolic-androgenic steroid therapy in the treatment of chronic diseases. J Clin Endocrinol Metab 2001; 86: 5108-5117.

21. Borsheim E, Tipton KD, Wolf SE, Wolfe RR. Essential amino acids and muscle protein recovery from resistance exercise. Am J Physiol Endocrinol Metab 2002; 283: E648-E657.

22. Engelen MP, Deutz NE, Wouters EF, Schols AM. Enhanced levels of whole-body protein turnover in patients with chronic obstructive pulmonary disease. Am J Respir Crit Care Med 2000; 162: 1488-1492.

23. Eid AA, Ionescu AA, Nixon LS, et al. Inflammatory response and body composition in chronic obstructive pulmonary disease. Am J Respir Crit Care Med 2001; 164: 1414-1418.

24. Pouw EM, Schols AM, Deutz NE, Wouters EF. Plasma and muscle amino acid levels in relation to resting energy expenditure and inflammation in stable chronic obstructive pulmonary disease. Am J Respir Crit Care Med 1998; 158: 797-801.

25. Mansoor O, Cayol M, Gachon $\mathrm{P}$, et al. Albumin and fibrinogen syntheses increase while muscle protein synthesis decreases in head-injured patients. Am J Physiol 1997; 273: E898-E902.

26. Morrison WL, Gibson JN, Scrimgeour C, Rennie MJ. Muscle wasting in emphysema. Clin Sci 1988; 75: 415-420.

27. Yoneda T, Yoshikawa M, Fu A, Tsukaguchi K, Okamoto Y, Takenaka H. Plasma levels of amino acids and hypermetabolism in patients with chronic obstructive pulmonary disease. Nutrition 2001; 17: 95-99.

28. Engelen MP, Wouters EF, Deutz NE, Menheere PP, Schols AM. Factors contributing to alterations in skeletal muscle and plasma amino acid profiles in patients with chronic obstructive pulmonary disease. Am J Clin Nutr 2000; 72: $1480-1487$.

29. Anthony JC, Anthony TG, Kimball SR, Jefferson LS. Signaling pathways involved in translational control of protein synthesis in skeletal muscle by leucine. J Nutr 2001; 131: 856S-860S.

30. Levenhagen DK, Gresham JD, Carlson MG, Maron DJ, Borel MJ, Flakoll PJ. Postexercise nutrient intake timing in humans is critical to recovery of leg glucose and protein homeostasis. Am J Physiol Endocrinol Metab 2001; 280: E982-E993.

31. Engelen MP, Schols AM, Does JD, Deutz NE, Wouters EF. Altered glutamate metabolism is associated with reduced muscle glutathione levels in patients with emphysema. Am J Respir Crit Care Med 2000; 161: 98-103.

32. Engelen MP, Wouters EF, Deutz NE, Does JD, Schols AM. Effects of exercise on amino acid metabolism in patients with chronic obstructive pulmonary disease. Am J Respir Crit Care Med 2001; 163: 859-864.

33. Rabinovich RA, Ardite E, Troosters $\mathrm{T}$, et al. Reduced muscle redox capacity after endurance training in patients with chronic obstructive pulmonary disease. Am J Respir Crit Care Med 2001; 164: 1114-1118.

34. Creutzberg EC, Schols AM, Weling-Scheepers CA, Buurman WA, Wouters EF. Characterization of nonresponse to high caloric oral nutritional therapy in depleted patients with chronic obstructive pulmonary disease. Am J Respir Crit Care Med 2000; 161: 745-752.

35. Debigare $\mathrm{R}$, Cote $\mathrm{CH}$, Maltais F. Peripheral muscle wasting in chronic obstructive pulmonary disease. Clinical relevance and mechanisms. Am J Respir Crit Care Med 2001; 164: 1712-1717.

36. Calder PC. Polyunsaturated fatty acids, inflammation, and immunity. Lipids 2001; 36: 1007-1024.

37. Barber MD, Ross JA, Voss AC, Tisdale MJ, Fearon KC. The effect of an oral nutritional supplement enriched with fish oil on weight-loss in patients with pancreatic cancer. Br J Cancer 1999; 81: 80-86.

38. Grimble RF, Howell WM, O'Reilly G, et al. The ability of fish oil to suppress tumor necrosis factor alpha production by peripheral blood mononuclear cells in healthy men is associated with polymorphisms in genes that influence tumor necrosis factor alpha production. Am J Clin Nutr 2002; 76: 454459.

39. Sakao S, Tatsumi K, Igari H, Shino Y, Shirasawa H, Kuriyama T. Association of tumor necrosis factor alpha gene promoter polymorphism with the presence of chronic obstructive pulmonary disease. Am J Respir Crit Care Med 2001; 163: 420-422.

40. Sakao S, Tatsumi K, Igari $\mathrm{H}$, et al. Association of tumor necrosis factor-alpha gene promoter polymorphism with low attenuation areas on high-resolution $\mathrm{CT}$ in patients with COPD. Chest 2002; 122: 416-420. 
41. Gosker HR, van Mameren H, van Dijk PJ, et al. Skeletal muscle fibre-type shifting and metabolic profile in patients with chronic obstructive pulmonary disease. Eur Respir $J$ 2002; 19: 617-625.

42. Maltais F, LeBlanc P, Whittom F, et al. Oxidative enzyme activities of the vastus lateralis muscle and the functional status in patients with COPD. Thorax 2000; 55: 848-853.

43. Gosker HR, Wouters EF, van der Vusse GJ, Schols AM. Skeletal muscle dysfunction in chronic obstructive pulmonary disease and chronic heart failure: underlying mechanisms and therapy perspectives. Am J Clin Nutr 2000; 71: 1033-1047.

44. Baarends EM, Schols AM, Akkermans MA, Wouters EF. Decreased mechanical efficiency in clinically stable patients with COPD. Thorax 1997; 52: 981-986.

45. Maltais F, Simard AA, Simard C, Jobin J, Desgagnes P, LeBlanc P. Oxidative capacity of the skeletal muscle and lactic acid kinetics during exercise in normal subjects and in patients with COPD. Am J Respir Crit Care Med 1996; 153: 288-293.

46. Sala E, Roca J, Marrades RM, et al. Effects of endurance training on skeletal muscle bioenergetics in chronic obstructive pulmonary disease. Am J Respir Crit Care Med 1999; 159: 1726-1734.

47. Pouw EM, Schols AMWJ, Vusse van der GJ, Wouters EFM. Elevated inosine monophosphate levels in resting muscle of patients with stable COPD. Am J Respir Crit Care Med 1998; 157: 453-457.

48. Satta A, Migliori GB, Spanevello A, et al. Fibre types in skeletal muscles of chronic obstructive pulmonary disease patients related to respiratory function and exercise tolerance. Eur Respir J 1997; 10: 2853-2860.

49. Coppoolse R, Schols AM, Baarends EM, et al. Interval versus continuous training in patients with severe COPD: a randomized clinical trial. Eur Respir J 1999; 14: 258-263.

50. Ortega F, Toral J, Cejudo P, et al. Comparison of effects of strength and endurance training in patients with chronic obstructive pulmonary disease. Am J Respir Crit Care Med 2002; 166: 669-674.

51. Jakobsson P, Jorfeldt L, Henriksson J. Metabolic enzyme activity in the quadriceps femoris muscle in patients with severe chronic obstructive pulmonary disease. Am J Respir Crit Care Med 1995; 151: 374-377.

52. Sauleda J, Garcia-Palmer F, Wiesner RJ, et al. Cytochrome oxidase activity and mitochondrial gene expression in skeletal muscle of patients with chronic obstructive pulmonary disease. Am J Respir Crit Care Med 1998; 157: 1413-1417.

53. Glatz JF, Storch J. Unravelling the significance of cellular fatty acid-binding proteins. Curr Opin Lipidol 2001; 12: $267-274$.

54. Luiken JJ, Arumugam Y, Bell RC, et al. Changes in fatty acid transport and transporters are related to the severity of insulin deficiency. Am J Physiol Endocrinol Metab 2002; 283: E612-E621.

55. Tunstall RJ, Mehan KA, Wadley GD, et al. Exercise training increases lipid metabolism gene expression in human skeletal muscle. Am J Physiol Endocrinol Metab 2002; 283: E66-E72.

56. Abu-Elheiga L, Brinkley WR, Zhong L, Chirala SS, Woldegiorgis G, Wakil SJ. The subcellular localization of acetyl-CoA carboxylase 2. Proc Natl Acad Sci USA 2000; 97: 1444-1449.

57. Schrauwen P, Van Aggel-Leijssen DP, Hul G, et al. The effect of a 3-month low-intensity endurance training program on fat oxidation and acetyl-CoA carboxylase-2 expression. Diabetes 2002; 51: 2220-2226.

58. Clarke SD. Polyunsaturated fatty acid regulation of gene transcription: a mechanism to improve energy balance and insulin resistance. Br J Nutr 2000; 83: Suppl. 1, S59-S66.

59. Schoonjans K, Staels B, Auwerx J. The peroxisome proliferator activated receptors (PPARS) and their effects on lipid metabolism and adipocyte differentiation. Biochim Biophys Acta 1996; 1302: 93-109.

60. Lin J, Wu H, Tarr PT, et al. Transcriptional co-activator PGC-1 alpha drives the formation of slow-twitch muscle fibres. Nature 2002; 418: 797-801.

61. Baar K, Wende AR, Jones TE, et al. Adaptations of skeletal muscle to exercise: rapid increase in the transcriptional coactivator PGC-1. FASEB J 2002; 16: 1879-1886. 